\title{
Black water fever: secondary to dual infection with $P$. falciparum and $P$. Vivax \\ Authors
}

\author{
Dr Ayush Bansal ${ }^{1}$, Dr Ghanshyam Pangtey ${ }^{2}$, Dr Ashu Gupta ${ }^{3}$ \\ ${ }^{1}$ MD (Medicine), Senior Resident, Dept. of Medicine, Lady Hardinge Medical College and Associated \\ Hospitals, New Delhi \\ ${ }^{2}$ Professor in Dept of Medicine, Lady Hardinge Medical College and Associated Hospitals, New Delhi \\ ${ }^{3}$ DM Resident (Cardiology), Indira Gandhi Medical College, Shimla
}

\section{Introduction}

Black water fever is a relatively rare, but serious complication of malarial fever. It is more common in people living in endemic areas or people with repeated episodes of malaria. The incidence of black water fever had seen a dramatic decrease in 1950 with the replacement of quinine with chloroquine $^{(5)}$. But in recent years, resistance to chloroquine has led to the use of amino-alcohol drugs like mefloquine and halofantrine which has been associated with re-appearance of black water fever ${ }^{(6,7)}$. Use of artemisinin derivatives like artesunate and artemether have not shown to cause black water fever ${ }^{(4)}$. We report a case presenting to our hospital emergency with fever and cola colored urine.

\section{Case}

A 28 years old male patient presented to our medical emergency with history of fever for past three days which was high grade, intermittent, with chills and rigor. It was accompanied with black colored urine for the past two days. Patient had a pasthistory of malaria, two episodes in past two years. On examination, the patient was febrile and toxic, with a heart rate of $120 / \mathrm{min}$, blood pressure of $90 / 60 \mathrm{mmHg}$ and was having conjunctival congestion with icterus. There was hepatosplenomegaly. Initial laboratory examination revealed hemoglobin of $10.2 \mathrm{gm} \%$, WBC 4200/cumm, platelets 64000/cumm, hematocrit $31 \%$, total bilirubin $7.4 \mathrm{mg} \%$ (indirect 5.2), ALT $121 \mathrm{IU} / 1$, AST $74 \mathrm{IU} / \mathrm{l}, \mathrm{INR} 1.09$ and normal renal parameters. Urine examination revealed 30-40 RBC/cumm with hemoglobinuria. On peripheral smear, malarial parasitemia (gametocytesofPlasmodiumvivaxandfalciparum)w as documentedtobe $>4 \%$. Optimal antigen test was positive for both plasmodium vivax and falciparum. Dengue and leptospira serology were negative. The patient was started on injectable artesunate $3.2 \mathrm{mg} / \mathrm{kg}$ body weight on first day, followed by $2.4 \mathrm{mg} / \mathrm{kg}$ on subsequent days, along with other supportive fluid management. Clindamycin was also added as part of antimalarial therapy. The patient continued to have fever and cola colored urine for next two days and had a fall in hemoglobin to $8.1 \mathrm{gm} \%$ with platelet count of $45000 /$ cumm and hematocrit of $27 \%$. He was given one unit whole blood on the third day. Recovery started on the fourth day of treatment with return of appetite and the urine color improved. Anti-malarials were given for full seven days. The patient was not G6PD deficient and was discharged on oral primaquine. 


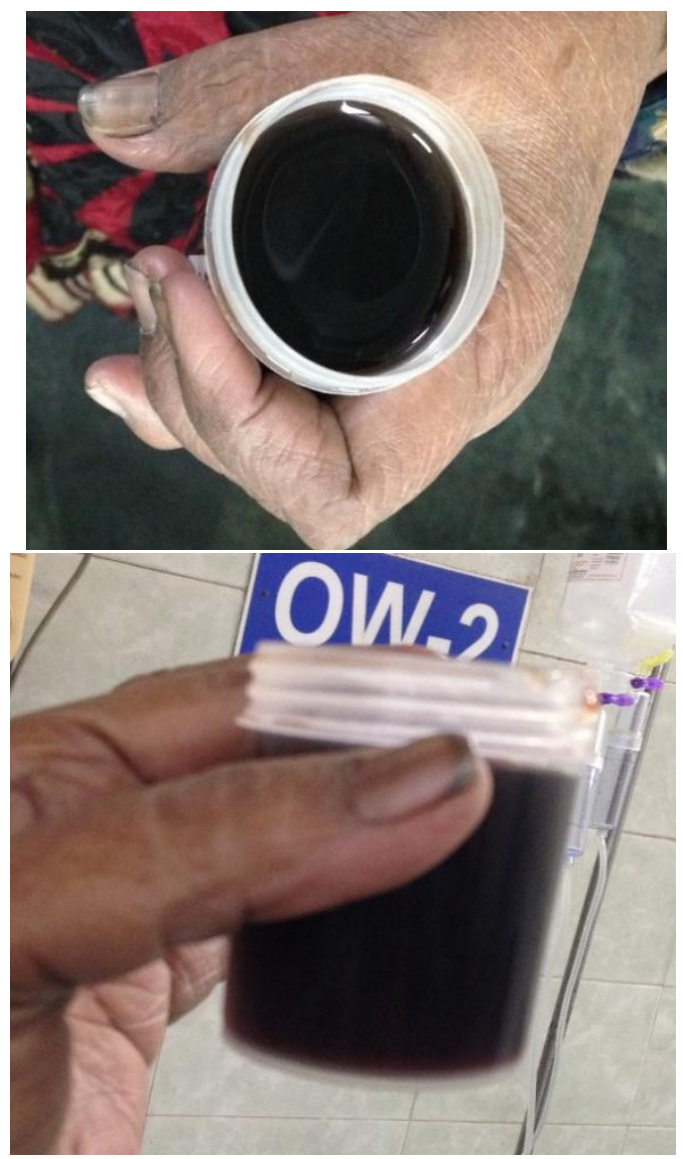

Figure 1 Urine on presentation (Day 1)

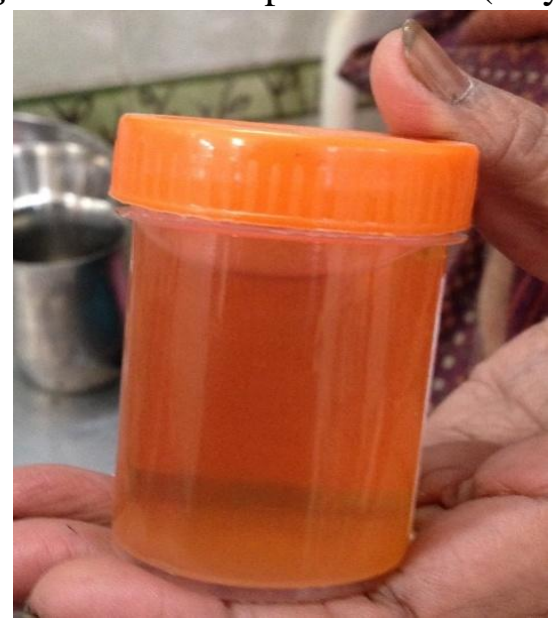

Figure 2Urine on Day 4.

\section{Discussion}

The term "black water fever" was coined and linked with malaria by Dr. John Farrell Easmon in1884 in his pamphlet entitled "the nature and treatment of black water, ${ }^{\text {, }}$.

It implies to excretion of blood pigment (hemoglobin) in the urine with absence of red blood cells or with an insufficient number to account for the alteration in the color of urine ${ }^{(9)}$. The high parasitic index of falciparum malaria leads to intravascular hemolysis, leading to indirect hyperbilirubinemia and release of hemoglobin in the blood vessels and subsequently into the urine which may cause renal failure. The exact mechanism behind hemolysis still remains unknown, though a recent report suggested that metabolism of quinine by the cytochrome P450 3A4 enzyme may be responsible for increasing oxidative stress within erythrocytes, making these cells more vulnerable to hemolysis ${ }^{(10)}$. Other causes which may lead to black water fever include patients of severe malaria treated with amino-alcohol drugs like quinine, mefloquine or halofantrine, or patients with G6PD deficiency ${ }^{(6)}$. Drugs such as artemisinin derivatives, chloroquine or piperaquine have significantly lower potential to cause hemolysis, particularly during the treatment of uncomplicated malaria ${ }^{(11)}$.

The treatment of black water fever includes antimalarial therapy, mainly with artemisinin derivatives, blood transfusion and other supportive measures. People living in endemic areas are more susceptible, therefore artemisinin derivatives are the drug of choice in endemic areas. According to WHO 2017 malaria report, travelers going to malaria endemic areas should take the same chemoprophylaxis treatment before, during and upon return from their travel. A timely diagnosis is must as the disease carries a high mortality.

\section{Prevention}

Prevention is the single most tool to promote health in a cost-effective manner. Insecticide treated bed nets, insecticides for spraying dwellings and highly effective drugs are being funded and distributed by CDC, UNICEF and $\mathrm{WHO}^{(1)}$. Malaria may be contained by judicious use of insecticides, rapid diagnosis, prompt management and chemoprophylaxis of travelers going to endemic regions.

\section{Chemoprophylaxis (1)}

Chemoprophylaxis is never entirely reliable and malaria should always be considered in the differential diagnosis of fever, in patients who have travelled to endemic areas even if they are taking prophylactic anti-malarial treatment.

Chloroquine is used in a dose of $300 \mathrm{mg}$ once weekly in chloroquine sensitive areas. For 
chloroquine resistant areas, doxycycline $100 \mathrm{mg}$ once daily or atovaquone-proguanil (250/100mg) 1 tablet stat is used. In pregnancy, mefloquine is the only drug advised in a dose of $250 \mathrm{mg}$ once weekly. Chloroquine and proguanil may also be used in pregnancy. All these drugs are given from 2 weeks before departure to 4 weeks after leaving endemic areas.

\section{Conclusion}

Black water fever is an uncommon but fatal complication of malaria, requiring a timely diagnosis and appropriate management. This paper aims to sensitize the clinicians about the resurgence of black water fever and chemoprophylaxis of malaria.

\section{References}

1. Nicholas $\mathrm{J}$ White, Joel G Breman; Harrison Principles of Int Med, $19^{\text {th }}$ edition, Vol 2, Sec 18, Chapter 248, Pg 1368-84.

2. Amar Pazare; Medicine Update 2016, Vol 2, Chapter 137, Pg 689.

3. Katongole-Mbidde E, Banura C, Kizito A (1988-03-19); “Black water fever caused by Plasmodium vivax infection in the acquired immune deficiency syndrome"; Br Med J (Clin Res Ed) 296(6625):827

4. World Health Organization, Division of Control of Tropical Diseases: Severe and complicated malaria. Trans R Soc Trop Med Hyg. 1990, 84 (Suppl 2): 1-65.

5. Bruce-Chwatt LJ. Quinine and the mystery of black water fever, Acta Leidensia, 1987, Vol 55 (Pg 181-96).

6. Vancot F, Fajac I, Gachot B, et al. Halofantrine and acute intravascular hemolysis, Lancet, 1992, Vol 340, Pg 90910.

7. Bruneel F, Gachot B, Wolff M, Regnier B, Danis M, Vachon F, corresponding group: Resurgence of black water fever in longterm European expatriates in Africa: report of 21 cases and review. Clin Infect Dis 2001, 32:1133-1140.

8. J Nephrol 2009, Nov-Dec Suppl 14:120-8; Black water fever: the rise and fall of an exotic disease; George CR.

9. Henry B. Gotten, M.D.; J.J Mac Gowan, M.D.; JAMA. 1940;114(16):1547. doi:10.1001/jama.

10. Marcsisin SR, Jin X, Bettger T, McCulley $\mathrm{N}$, Sousa JC, Shanks GD, et al CYP450 phenotyping and metabolite identification of quinine by accurate mass UPLC-MS analysis: a possible metabolic link to black water fever. Malar J. 2013, 12: 214-10.1186/1475-2875-12-214.

11. Malaria Journal 2014,13:96; Lon et al.; licensee BioMed Central Ltd. 